\title{
Field Performance of Five Soybean Mutants Under Drought Stress Conditions and Molecular Analysis Using SSR Markers
}

\author{
Yuliasti ${ }^{1^{*}}$ and Reflinur ${ }^{2}$ \\ ${ }^{1}$ Center for Isotopes and Radiation Application, National Nuclear Energy Agency, \\ Jl. Lebak Bulus Raya No. 49, Jakarta 12440, Indonesia \\ ${ }^{2}$ Indonesian Center for Agricultural Biotechnology and Genetic Resource Research and Development, \\ Jl. Tentara Pelajar No. 3A, Bogor, Indonesia
}

\section{ARTICLE INFO}

Article history:

Received 19 November 2015

Received in revised form 03 March 2017

Accepted 06 March 2017

Keywords:

Supply some 4-6 keywords

Soybean

Mutant

Drought tolerance

SSR markers analysis

\begin{abstract}
A B S T R A C T
The objectives of this research were to evaluate (1) the performance of soybean mutant lines under drought stress conditions, and (2) the genetic diversity and relationship among the mutant lines using SSR markers. The field evaluation was conducted during the dry season of 2011 and 2012 at the experimental Farm of Mataram University, West Nusa Tenggara, Indonesia. The field experiment was set up in a randomized block design. Ten mutant lines and two control varieties were evaluated in four replications. Genetic distance among evaluated lines were determined based on allelic diversity analysis using 40 simple sequence repeat (SSR) loci. Under drought stress conditions, two mutant lines, Kdl3 and Kdl8, showed a better performance compared to the other ones. The high yielding mutant lines were $\mathrm{Kdl} 3$ and $\mathrm{Kdl} 8$, which yielded 1.75 t ha- 1 and $1.69 \mathrm{t}$ ha-1, respectively, compared to the parent and national control, Panderman 1.43 t ha-1 and Muria $1.32 \mathrm{t}$ ha-1. These mutant lines required 30.75 to 32 days to flower and 79.75 to 83.75 day to harvest with relatively short plant height 28.25 and $23.35 \mathrm{~cm}$ respectively. Those mutant characters were better than those of the other three mutants, the original parents, and the control soybean species. Since the evaluated soybean mutant lines yielded more under drought stress conditions than the standard varieties, they can be used and registered as drought-tolerant soybean mutants. Moreover, the evaluated soybean accessions showed a wide genetic distance. The accessions were clustered into two groups according to their genetic background, namely group I (the Panderman with three mutant lines) and group II (the Muria with two mutant lines). Twenty-three out of 40 evaluated SSR loci, including AW31, BE806, CMAC7L, S080, S126, S57, S171, S224, S285, S294, S393, S294, S383, S511, S511, S520, S540, S547, S551, S571, S577, and S578, provided polymorphic alleles between the parents and their mutants and could be used to differentiate mutants from their parents. Therefore, these loci are informative and may be useful for further analysis of soybean mutant lines in relation to breeding program.
\end{abstract}

(C) 2017 Atom Indonesia. All rights reserved

\section{INTRODUCTION}

Soybean (Glycine max) is the world's most widely grown seed legume, providing an inexpensive source of protein and vegetable oil with an average content of $40 \%$ protein and $20 \%$ oil, respectively, for human consumption. This important legume crop is adapted to grow in a wide

${ }^{*}$ Corresponding author.

E-mail address: yuliasti@batan.go.id

DOI: https://doi.org/10.17146/aij.2017.685 range of climatic conditions; however, soybean growth, development, and yield are greatly affected by several abiotic stresses, such as drought [1].

The consumption of soybean in Indonesia has been increasing recently, but the production has been decreasing. Therefore, to supply the domestic demand, it is important to increase the domestic production of soybean. The means to increase the production includes the expansion of the growth areas and the use of adapted varieties tolerant to drought. However, the wide area of marginal lands 
in Indonesia, such as dry land and acid soil, become a major factor limiting plant expansion. The development of new soybean genotypes being tolerant to drought stress with high grain yield will therefore be important in order to anticipate yield losses of soybean cultivated in the marginal land. So far, different breeding approaches have been employed to produce genetic improvements to meet the industrial and agricultural requirements. Through various programs, the government puts a strong effort to increase soybean production toward self-sufficiency.

Induced mutation is a secure way to improve genetic diversity, including in soybean, through development of mutant lines based on the utilization of gamma radiation in vivo and in vitro followed by their utilization in breeding programs [2]. Mutation breeding by using gamma irradiation is an effective procedure in plant breeding which can be widely used to induce genetic recombination. Up to date, more than 2600 mutant varieties with desirable quantitative and qualitative traits have been introduced. Pavadai obtained favorite traits using physical mutagens in soybean [3] and advocated the importance of induced mutations as one of the most effective and efficient approaches to regenerate and restore the genetic variability in chickpea. Mutation breeding is probably an effective tool for generating variability in the existing varieties and selecting lines with desirable characters which proved to be an ideal crop for abiotic stresses [4]. Among the abiotic stresses, drought is a significant limiting factor for agricultural productivity and generally inhibits plant growth through reduced water absorption and nutrient uptake [5].

In the present study, mutant soybean lines derived from the Panderman cultivar were generated through irradiation treatment using gamma radiation at $300 \mathrm{~Gy}$. These soybean mutant lines were generated to the M5 generation developed by bselfing method from the primary mutant lines in previous experiment. The purpose of generating those mutants was to develop new soybean lines conferring superior characters such as high yield, high protein level, and high vitamin and nutrition contents. In this study, the yield of the mutant soybean lines under marginal land conditions was evaluated. Specifically, the yield evaluations were conducted in dry land, in order to inhibit growth and to test the soybean mutant lines genotypes.

Recent advances in molecular biology, principally the development of polymerase chain reaction (PCR) for amplifying DNA, DNA sequencing, and data analysis have resulted in powerful techniques that can be used for screening, characterization, and evaluation of genetic diversity. With molecular marker techniques, powerful tools have been developed to accurately assess and characterize genetic resources [6].

Microsatellites or simple sequence repeat (SSR) markers has been known to have a high resolving power for detecting population [7]. Microsatellites, a short tandem repetitive DNA sequences with a repeat length of a few (one to five) base pairs, have become the molecular markers of choice for a wide range of applications such as genetic mapping and genome analysis, genotype identification and variety protection, seed purity evaluation and germplasm conservation, diversity studies, paternity determination and pedigree analysis, gene and quantitative trait locus analysis, and marker-assisted breeding [8]. A total of nine SSR markers were successfully identified in the three mungbean mutant lines. The MB122A SSR primer was identified as the best primer for mutant analysis and the SSR markers could be utilized well to analyze the mutants at DNA level [9].

The objectives of this research were to evaluate (1) the performance of soybean mutant lines under drought stress conditions and (2) the genetic diversity and relationship among the mutant lines using SSR markers.

\section{EXPERIMENTAL METHODS}

\section{Plant materials}

SSRs offer a potentially attractive combination of features that are useful as molecular markers. First, SSRs have been reported to be highly polymorphic and highly informative in plants, providing many different closely related individuals. Second, SSRs can be analyzed by a rapid, technically simple, and inexpensive PCR-based way that requires only small quantities of DNA. Third, SSRs are co-dominantly inherited and simple Mendelian segregation has been observed. Finally, SSRs are both abundant and uniformly dispersed in plant genomes.

A total of ten soybean mutant lines (Kdl 1-9 and G4) were used in this study. These mutant lines were derived from mutations induced through gamma rays irradiation at the Indonesian Center for Isotopes and Radiation Application (CIRA) BATAN. Ten soybean mutant lines were generated from cv Panderman by irradiation treatment using gamma radiation at $300 \mathrm{~Gy}$. Selfing up to M5 generation was conducted from the primary mutant lines from previous experiment. The yield of these mutant lines were tested to select a promising soybean mutant lines tolerant to drought stress with high yield. The two control varieties, the Panderman and the Muria, were also included in this study. 


\section{Field experiment}

Plant genetic materials, including ten soybean mutant lines (Kdl 1-9 and G4) and two control plants (Panderman and Muria) were grown directly during dry season ( August 2012 October 2012) to evaluate their responses against drought stress at the field experiment sites in Lombok Barat and Lombok Timur, West Nusa Tenggara province. The field experiment was laid out in a randomized block design with three replications for each treatment. The growth and yield of the selected drought tolerant plants were evaluated in the field condition. A combined analysis of variance was performed, based on the randomized complete block design.

The design (RCBD) and comparison of quantitative traits means based on Duncan's new multiple range test (DNMRT) were performed in the SAS software package (2001) [10].

\section{Molecular analysis}

\section{DNA extraction and SSR analysis}

Five mutant lines showing high yield under drought condition were selected and subjected to molecular analysis. DNA was extracted from young leaves using a standard cetyltrimethylammonium bromide (CTAB) method [11]. The concentration of the DNA samples was determined with a spectrophotometer and DNA samples were diluted to $50 \mathrm{ng} / \mu \mathrm{l}$ for analysis using SSR markers. A total 23 SSR primers derived from soybean sequences. Hisano et al. [12] were used in this study. PCR analysis was performed in a total volume of $15 \mu \mathrm{l}$ that contained $20 \mathrm{ng} / \mu \mathrm{l}$ of genomic DNA, $0.25 \mu \mathrm{M}$ of each primer (forward and reverse), $0.125 \mathrm{mM}$ of each dNTPs, 0.15 units of TaqDNA polymerase, and $1 \times$ reaction buffer. The PCR amplification was performed in a thermal cycler and consisted of an initial denaturation step of $3 \mathrm{~min}$ at $94{ }^{\circ} \mathrm{C}$, followed by 35 cycles at $94{ }^{\circ} \mathrm{C}$ for $45 \mathrm{~s}, 47$ to $57{ }^{\circ} \mathrm{C}$ (depending upon the annealing temperature of the primer pair) for $30 \mathrm{~s}, 72{ }^{\circ} \mathrm{C}$ for $1 \mathrm{~min}$, and 1 cycle of $72{ }^{\circ} \mathrm{C}$ for $10 \mathrm{~min}$. PCR products were separated on $6 \%(\mathrm{w} / \mathrm{v})$ non-denaturation polyacrylamide gel electrophoresis and stained in ethidium bromide solution PCR products (amplifications) were then visualized and documented under UV light using ChemiDoc (Bio-Rad, USA).

\section{Data analysis}

Combined analysis of variance based on randomized complete block design (RCBD) and comparison of quantitative traits means based on Duncan's new multiple range test (DNMRT) were performed [13]. PCR products amplified by SSR markers were scored visually for their presence (1) or absence (0). A dendrogram was constructed based on Jaccard's similarity coefficient (with unweighted pair group method and arithmetic average (UPGMA) using the NTSYS-pc version 2.02 by Rohlf FJ. NTSYS-pc 2000 [14].

\section{RESULTS AND DISCUSSION}

The grain yield of soybean crop is a function of cumulative effect of various yield components, which are influenced by genetic makeup of the variety, various agronomic practices, and environmental conditions. The data on soybean yield was subjected to statistical analysis and significant differences were found among the mutant lines and control plant under drought condition (Table 1). Drought is deleterious for plant growth and yield $[15,16]$ and is one of the most important limiting factors in agriculture [17]. In dry season, a significant increase in grain yield of about $12 \%$ compared to the original variety was found in mutant lines Kdl3 and Kdl8. Moreover, the Kdl3 mutant line also had a significantly higher 100-grain weight of $26.67 \mathrm{~g}$ than the original variety Pandermant of $20.95 \mathrm{~g}$. The soybean mutant lines of $\mathrm{Kdl3}$ and $\mathrm{Kdl} 8$ produced grain yields of up to 1.75 and 1.69 t ha-1, respectively. These yields were significantly higher in comparison to their original variety, the Panderman $\left(1.43 \mathrm{t} \mathrm{ha}^{-1}\right)$, and the national check variety Muria $\left(1.32 \mathrm{t} \mathrm{ha}^{-1}\right)$. From these data it can be concluded that the mutant lines $\mathrm{Kdl} 3$ and Kd18 were promising lines for cultivation in dry season (Table 1). Considering that seed weight and number of pods in a plant are the major components of grain yield, the superiority in the 100-grain seed weight is important in plant breeding to improve the grain yield [18]. The mutant line Kdl3 grown in the dry season attained a plant height of $28.25 \mathrm{~cm}$, significantly shorter than the Panderman's $43.75 \mathrm{~cm}$. The mutant line Kdl3 showed superior characters in requiring fewer days to flowering (30.75) and fewer days of maturity (79.75) in comparison to the control plants. Yield, as measured by the weight of seeds, is reduced most by stresses occurring during early formation and pod-filling stages. Water stress during early reproductive growth (flowering and pod set) reduces yield, usually as a result of fewer pods and seeds per unit area. It is considered that abortion of flowers and pods due to water stress in flowering and pod set stages are the main reason for reducing number of pod and seed per plant. 
The number of pods and seeds per plant are the most important yield components of soybean that are reduced under water stress conditions [19].

Table 1. Yield performance of soybean mutant lines under drought environmental condition

\begin{tabular}{llllll}
\hline $\begin{array}{c}\text { Mutant } \\
\text { /Variety }\end{array}$ & Yield/ha & $\begin{array}{c}\text { 100 grain } \\
\text { Weight }(\mathrm{g})\end{array}$ & $\begin{array}{c}\text { Days to } \\
\text { Flower } \\
\text { s }\end{array}$ & $\begin{array}{c}\text { Days to } \\
\text { Maturity }\end{array}$ & $\begin{array}{c}\text { Plant } \\
\text { height } \\
(\mathbf{c m})\end{array}$ \\
\hline 1 KDL 1 & $1.08 \mathrm{~d}$ & $20.4 \mathrm{~d}$ & $32.62 \mathrm{a}$ & $76.75 \mathrm{f}$ & $26.5 \mathrm{c}$ \\
$2 \mathrm{KDL} 2$ & $1.45 \mathrm{~b}$ & $24.96 \mathrm{bc}$ & $31.25 \mathrm{c}$ & $75.75 \mathrm{e}$ & $28.87 \mathrm{~b}$ \\
$3 \mathrm{KDL} 3$ & $1.75 \mathrm{a}$ & $26.67 \mathrm{a}$ & $30.75 \mathrm{~d}$ & $79.75 \mathrm{e}$ & $28.25 \mathrm{~b}$ \\
$4 \mathrm{KDL} 4$ & $1.24 \mathrm{c}$ & $25.6 \mathrm{bc}$ & $32.22 \mathrm{ab}$ & $80.75 \mathrm{~d}$ & $21.5 \mathrm{e}$ \\
$5 \mathrm{KDL} 5$ & $1.22 \mathrm{c}$ & $24.37 \mathrm{c}$ & $32.5 \mathrm{a}$ & $82.25 \mathrm{c}$ & $28.75 \mathrm{~b}$ \\
$6 \mathrm{KDL6}$ & $1.30 \mathrm{c}$ & $27.6 \mathrm{a}$ & $32.0 \mathrm{ab}$ & $82.25 \mathrm{c}$ & $27.5 \mathrm{~b}$ \\
$7 \mathrm{KDL} 7$ & $1.47 \mathrm{~b}$ & $27.02 \mathrm{a}$ & $31.5 \mathrm{c}$ & $83 \mathrm{c}$ & $30.7 \mathrm{~b}$ \\
$8 \mathrm{KDL} 8$ & $1.69 \mathrm{a}$ & $24.55 \mathrm{c}$ & $32 \mathrm{ab}$ & $83.75 \mathrm{c}$ & $23.25 \mathrm{~d}$ \\
9 KDL9 & $1.34 \mathrm{c}$ & $25.7 \mathrm{~b}$ & $32.37 \mathrm{ab}$ & $80.5 \mathrm{e}$ & $24.12 \mathrm{~d}$ \\
Panderman & $1.43 \mathrm{~b}$ & $20.95 \mathrm{~d}$ & $33.12 \mathrm{a}$ & $86.5 \mathrm{~b}$ & $43.75 \mathrm{a}$ \\
Muria & $1.32 \mathrm{c}$ & $18.85 \mathrm{f}$ & $31.7 \mathrm{ab}$ & $77 \mathrm{f}$ & $28.5 \mathrm{~b}$ \\
G4 & $1.43 \mathrm{c}$ & $22.65 \mathrm{~d}$ & $30.75 \mathrm{~d}$ & $88.5 \mathrm{a}$ & $25.79 \mathrm{c}$ \\
\hline
\end{tabular}

Notes: Values followed by same letters with in a row are not significantly different by Duncan Multiple Range Test $(\mathrm{P}, 0.05)$

\section{SSR analysis}

Molecular profiling of a crop is the preferred choice in breeding program as this method is more reliable and authentic and less influenced by environmental fluctuations. Genetic profiling can identify the presence of unique bands that help in the identification of specific genotypes. Such markers are highly reliable in the establishment of genetic relatedness among the tested genotypes. Similar results were reported [20] in different crop species.

The polymorphic information content (PIC) value is a measure of the allelic differentiation. A total of 68 alleles with an average of 3.091 alleles per locus were detected. The polymorphic information content (PIC) among genotypes varied from 0.124 (S557) to 744 (S383). The PIC value is a measure of the allelic differentiation. The highest PIC value was observed for the marker Satt S383 $(0.744)$ and the lowest $(0.124)$ was for the markers S577, while the average PIC value was 0.415 (Table 2). Eight SSR markers (S171, S224, S244, S393, S520, S540, S547, and Satt551) had PIC values of greater than 0.45 and hence were the most informative ones for distinguishing among the soybean mutant lines (Tabel 2). Similarly to our results, A. Bisen (2015) [21] found that (PIC) among soybean genotypes varied from 0.049 (Sat_243 and Satt337) to 0.526 (Satt431) with an average of 0.199 .

The SSR evaluation carried out in the present study can be useful to determine the variation among mutant lines and to discriminate the mutants from the wild type at molecular level.
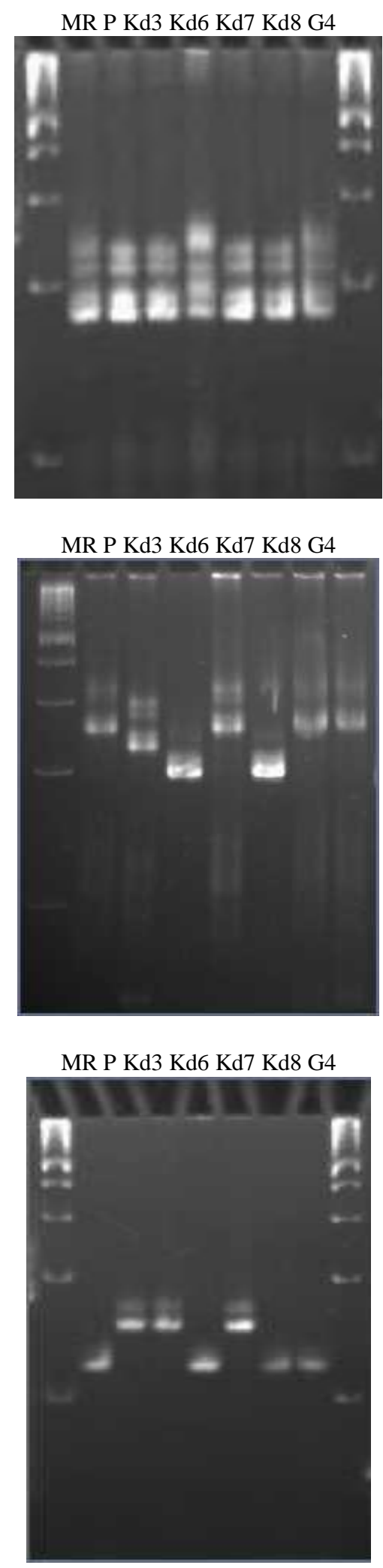

Fig. 1. SSR profile of soybean mutant lines amplified by S294 and Sat 126 (MR, P, Kd3, Kd6, Kd7, Kd8, G4) G4=mutant soybean: $\mathrm{P}=$ wild type Lanes $\mathrm{M}, 100 \mathrm{bp}$.

Of the total of 40 SSR primers used in discriminating the five soybean mutants and the two parental lines, nine primers exhibited polymorphism (Table 2). The primer pairs used showed 68 alleles distributed throughout 23 loci. The number of 
alleles per locus ranged from two to six, with an average of 3.091. Among the genomic SSR, the locus S171 from the linkage group (LG) S541 had the highest number of whereas S58, from AWE311, presented the lowest number of alleles. Among the SSR, locus S540 had the highest number of alleles at six. Similar results were found by analysis of soybean genetic diversity and relatedness among 25 soybean genotypes from Thailand, presented in [19], that revealed five alleles $(144,147,153,165$, and $168 \mathrm{bp}$ ) for Satt005, three alleles $(128,134$, and $149 \mathrm{bp)}$ for Satt309, and five alleles for Satt 183. An advanced polymorphism was detected for the loci S383 and 393 in the mutant lines and the Panderman variety (Fig. 1), which proves the efficiency of the utilization of these loci for testing genotypic variability. The results of this study are in agreement with [22] that carried out genetic diversity analysis in 100 sorghum genotypes for drought tolerance using 13 stay-green specific polymorphic SSR markers [23]. The work revealed high level of polymorphism among the genotypes; there, about 56 scorable alleles were generated, of which 55 were polymorphic, and the number of alleles produced by different primers ranged from two to seven with an average of 4.0 alleles per primer. Similar results have also been found that SSR have higher resolving power for detecting population structure and estimating genetic diversity than SNP in a sample of 303 accessions of domesticated soybean and its wild progenitor Glycine soja [7].

Table 2. Summary statistics of 12 polymorphic SSR primers genotyped on soybean mutant lines

\begin{tabular}{lccccc}
\hline Marker & $\begin{array}{c}\text { Major. } \\
\text { Allele. } \\
\text { Frquency }\end{array}$ & $\begin{array}{c}\text { Allele } \\
\text { No }\end{array}$ & $\begin{array}{c}\text { Gene } \\
\text { Diversity }\end{array}$ & $\begin{array}{c}\text { Heterozy } \\
\text { gosity }\end{array}$ & PIC \\
\hline AW31 & 0.857 & 2 & 0.245 & 0.000 & 0.215 \\
BE806 & 0.857 & 2 & 0.245 & 0.000 & 0.215 \\
CMAC7L & 0.857 & 2 & 0.245 & 0.000 & 0.215 \\
S080 & 0.857 & 2 & 0.245 & 0.000 & 0.215 \\
S126 & 0.571 & 2 & 0.490 & 0.000 & 0.370 \\
S57 & 0.857 & 2 & 0.245 & 0.000 & 0.215 \\
S171 & 0.429 & 4 & 0.622 & 1.000 & 0.547 \\
S224 & 0.429 & 4 & 0.622 & 1.000 & 0.547 \\
S244 & 0.571 & 4 & 0.582 & 0.143 & 0.520 \\
S285 & 0.571 & 2 & 0.490 & 0.286 & 0.370 \\
S294 & 0.714 & 2 & 0.408 & 0.000 & 0.325 \\
S393 & 0.357 & 5 & 0.745 & 1.000 & 0.704 \\
S383 & 0.357 & 6 & 0.776 & 0.714 & 0.744 \\
S511 & 0.857 & 2 & 0.245 & 0.000 & 0.215 \\
S520 & 0.286 & 4 & 0.745 & 1.000 & 0.697 \\
S540 & 0.357 & 6 & 0.755 & 0.714 & 0.719 \\
S547 & 0.357 & 5 & 0.714 & 0.857 & 0.666 \\
S551 & 0.286 & 4 & 0.745 & 1.000 & 0.697 \\
S571 & 0.857 & 2 & 0.245 & 0.000 & 0.215 \\
S577 & 0.929 & 2 & 0.133 & 0.143 & 0.124 \\
S578 & 0.571 & 2 & 0.490 & 0.000 & 0.370 \\
S581 & 0.857 & 2 & 0.245 & 0.000 & 0.215 \\
Mean & 0.620 & 3.091 & 0.467 & 0.357 & 0.415 \\
\hline Total & & 68 & & & \\
\hline & & & & &
\end{tabular}

Similarly to our results, a previous study of soybean genetic diversity and relatedness among 25 soybean genotypes from Thailand revealed five alleles $(144,147,153,165$, and $168 \mathrm{bp})$ for Satt005, three alleles $(128,134$, and $149 \mathrm{bp})$ for Satt309, and five alleles for Satt183 [20].

Based on UPGMA cluster analysis (Fig. 2), the accessions were clustered into two groups according to their genetic background, such as group I (the Panderman with three mutant lines) and group II (the Muria with two mutant lines). Twenty-three out of 40 SSR loci evaluated (AW31, BE806, CMAC7L, S080, S126, S57, S171, S224, S285, S294, S393, S294, S383, S511, SATT511, S520, SATT540, S 547, S551, S571, S577, and S578) yielded polymorphic allele between the parents and their mutants and can be used to differentiate mutants from their parents. Therefore, these loci may be used for further analysis of soybean mutants in the future breeding programs.

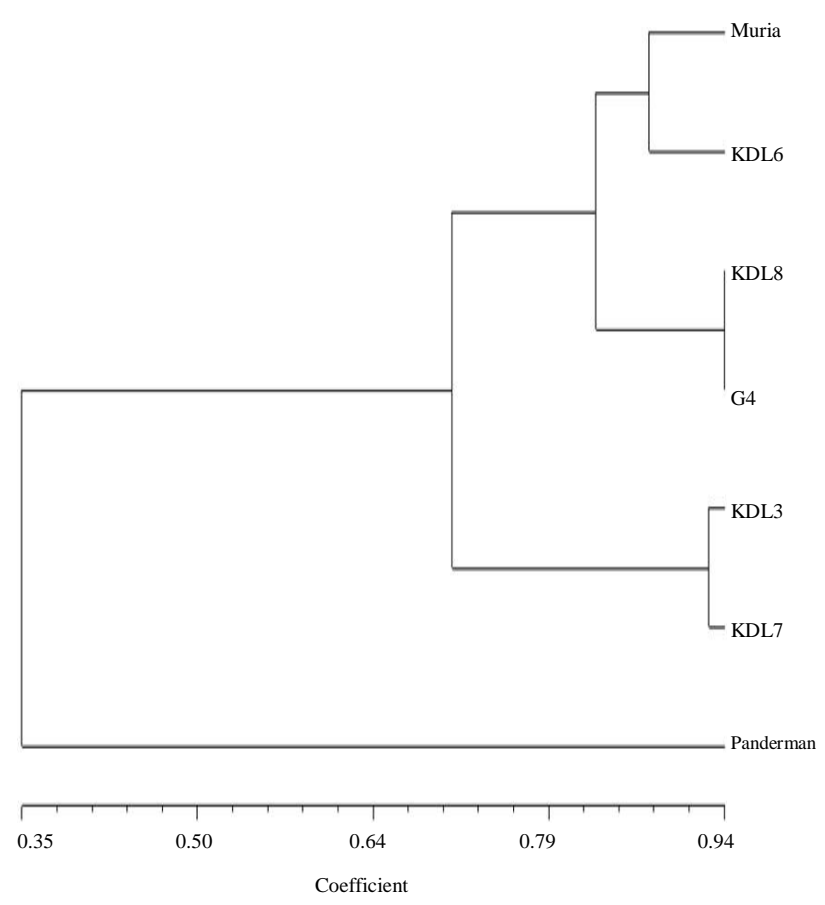

Fig. 2. Dendrogram of soybean mutant lines based on an unweighted pair group mean average (UPGMA) cluster analysis using the Jaccard's similarity coefficient for five soybean mutant lines.

The present study resulted in a set of SSR markers that enabled the differentiation between soybean mutant lines and the parental lines. These genetic materials can be exploited in molecular breeding by combining with mutation breeding to improve soybean varieties. Information on genetic distances based on microsatellite markers shall be preferred in creating selectable genetic variation using genotypes that are genetically apart [20]. 


\section{CONCLUSION}

Two mutant lines (Kdl3 and Kdl8) showed better performance than the other mutant lines and the control parents under drought stress conditions. These mutant lines required 30.75 to 32 days to flower and 79.75 to 83.75 days to harvest. They also have relatively short plant height 28.25 and $23.35 \mathrm{~cm}$, respectively. Those mutant's characters are better than those of the other three mutants, the original parents, and the control soybean varieties.

The high-yielding mutant lines were $\mathrm{Kdl} 3$ and $\mathrm{Kdl} 8$, in comparison to the parents and national controls.

The evaluated soybean accessions showed a wide genetic distance. The accessions were clustered into two groups according to their genetic background, namely group I (the Panderman with three mutant lines) and group II (the Muria with two mutant lines). Twenty-three out of 40 SSR loci evaluated (AW31, BE806, CMAC7L, S080, S126, S57, S171, S224, S285, S294, S393, S294, S383, S511, S511, S520, ST540, S547, S551, S571, S577, and S578) yielded polymorphic allele between the parents and their mutants and can be used to differentiate mutants from their parents. Therefore, these loci may be used for further analysis of soybean mutants in the future.

\section{ACKNOWLEDGMENT}

Financial supports from Center for Isotopes and Radiation Application (CIRA) - BATAN are acknowledged and greatly appreciated. The authors would like to express their gratitude to the Ministry of Research and Technology for including soybean in the grant program of 2011-2012.

\section{REFERENCES}

1. P.P. Mohammadi, A. Moieni, Hiraga et al., J. Proteomics 75 (2012) 1906e1923.

2. P. Pavadai, M. Girija and D. Dhanavel, J. Exp. Sci. 1 (2010) 8.

3. Mehdi-Younessi Hamzekhanlu, Ali IzadiDarbandi, Nejat Pirvali-Beiranvand et al., African Journal of Agricultural Research 6 (2011) 1779.

4. T. Yildirim, H. Canci and N.E. Turk, J. Field Crops. 18 (2013) 78.

5. M. Pour-Siahbidi, J. Hoseinzadeh, AR. PourAboughadareh et al., International Journal of Biosciences 3 (2013) 126.
6. Nguyen Thi Lang, Bui Phuoc Tam, Nguyen Van Hieu et al., SABRAO Journal of Breeding and Genetics 46 (2014) 1.

7. Y-H. Li, W. Li, C. Zhang et al., New Phytologist Trust. 188 (2010) 242.

8. A. Munir, S. Armghan, M. Iqbal et al., Hirani AH AJCS. 7 (2013) 66.

9. Yuliasti and Reflinur, Atom Indonesia (2015) 161.

41

10. Anonymous, SAS User's Guide, release 8.2. Statistical Analysis Systems Institute, Cary, NC (2001) 1.

11. S.B. Gelvin and C.N. Liu, Genetic Manipulation of Agrobacterium Tumefaciens Strains to Improve Transformation of Recalcitrant Plant Species, in: Plant Molecular Biology Manual, Chapter 6 Vol. 2, Kluwer Academic Publisher, Belgium (1994) 85.

12. H. Hisano, S. Sato, S. Isobe et al., DNA Res. 6 (2007) 257.

13. M.F. Collins and E. Kartini, Superionic Conduction in Silver Oxysalt-Silver Salt Glasses, Recent Research Development of Solid State Ionics Vol. I, S.G. Pandalay (Ed.), Transworld Research Network, India (2003) 167.

14. F.J. Rohlf, NTSYSpc Numerical Taxonomy and Multivariate Analysis System Version 2.1 User Guide, Applied Biostatistics Inc., New York (2000) 1.

15. G. Abdel, Thahir and I.M. Al-Rawi, Bioscience 1 (2011) 3.

16. V. Vinu, N. Singh, S. Vasudev et al., Int. J. Trop. Biol. 61 (2013) 1919.

17. M. Nabizade, T. Saki Nejad and M. Mojadam, Journal of American Science 7 (2011) 7.

18. A.A. Lalinia, N.M. Hoseini, M. Galostian et al., International J. of Agronomy and Plant Production 3 (2012) 599.

19. M. Zare, B. Dehghani and O. Alizadeh Arash Azarpana, International Journal of Farming and Allied Sciences 2 (2013) 19.

20. Soheil Kobraee, Keyvan Shamsi and Behrooz Rasekhi, Annals of Biological Research 2 (2011) 423.

21. B. Anchal, D. Khare, P. Nair et al., Physiology and Molecular Biology of Plants 21 (2015) 109. 
22. P. Tantasawat, J. Trongchuen, T. Prajongjai et al., AJCS 5 (2011) 3.
23. K. Rajarajan and K. Anesamurthy, Indian Journal of Genetics 1 (2011) 71. 